\title{
How Distorted Thinking Influence Marketing?
}

\author{
Emad Gith \\ Correspondence: Emad Gith, PhD, Sakhnin Academic College for Teacher Education, Sakhnin 20173, Israel; \\ Educational Psychological Services in Arraba Village, Israel 30812; Department of Psychology, Ethics, and Law, \\ International Center for Health, Law, and Ethics, Faculty of Law at the University of Haifa, Haifa, Israel 3498838.
}

Received: March 31, 2018

doi:10.11114/ijce.v1i1.3247
Accepted: April 20, $2018 \quad$ Online Published: April 27, 2018

URL: https://doi.org/10.11114/ijce.v1i1.3247

\begin{abstract}
The purpose of the current study was to examine the relation between the Cognitive Distortion marketing among Arabs in Israel. The results indicated that cognitive distortion positively related to marketing. there is a positive correlation between Binocular Vision Cognitive distortion marketing and between using polarized thinking Cognitive distortion marketing and between Should or must thinking Cognitive distortion marketing, similarly, between Catastrophizing Cognitive distortion marketing. This finding is in line with Nasir, et al. (2011) results that cognitive distortion is associated with marketing and misleading the buyers to buy things. Therefore, the researchers recommend that appropriate cognitive thinking should be used in marketing, this will increase earning and encourage marketing.
\end{abstract}

Keywords: distorted thinking, marketing

\section{Introduction}

Distorted thinking is defined as negative biased information processing (Beck, 1985). These thoughts distort reality and affect an individual's perception of reality, it causes the individual's mind to be convinced in untrue something by giving rational reasoning (McGrath \& Repetti, 2002). There are distorted thinking types: Binocular vision taking the negative details and magnify them filtering the positive aspects from the situation. Polarized thinking (black or white), Dark glasses (seeing only negative thought), Labeling and mislabeling (attaching negative label to the individual), Should or must thinking, Catastrophizing (expecting a disaster). Control fallacies, the individual sees himself as controlled but helpless. Moreover, overgeneralizing, personalizing and jump to conclusion.

Factors correlating with marketing strategies should be interesting area of investigation (Bahrami and Bahrami, 2015). Evidence has shown how such thinking distortions are related to marketing. Under negative stress, our executive functioning and reasoning capabilities can be overpowered and influence individual buying or marketing. In marketing, however, the world is often presented as yes or no, black or white, good or bad, for or against. The buyers often convince the buyer, he will not be in control of his perceptions and decisions, which lead the buyer to be manipulated into buying something. They create narratives around products that we can grasp quickly at a simple, emotional level, they use distorted thing to influence the individual mind (Nasir, et al.,2011).

Thus, the present study therefore focuses on individual cognitive distortion as related factor of marketing. To this end, the current study the hypothesis: cognitive distortion is related significantly to marketing and being convinced to buy products.

Aim of the present study

The present study aimed to extend the existing literature by examining whether and how distorted thinking influence marketing.

\section{Method}

\subsection{Participants}

Data was collected from 102 Arab participants from north Israel of whom 50 were male and 52 female.

The mean age was 25 years $(\mathrm{SD}=.34)$.

\subsection{Instrumentation}

Thinking distortions were measured using the Negative Cognitive Error Questionnaire (CNCEQ; Leitenberg et al., 
1986). The questionnaire contained 24-items, it provides scales scores of: catastrophizing, overgeneralization, personalizing and selective abstraction. Every subscale contains six scenarios (two social, two academic and two athletic) and a possible negative interpretation. The parent has to respond from 1 (Not at all like I would think) to 5 (Almost exactly like I would think) how the items indicate his/her tendency toward thinking distortions.

In the vein of internal reliability of the questionnaire, it was reported in Leitenberg et al. (1986) and has this measure been used in subsequent research with children (e.g. Weems et al., 2001).

Marketing influence: Marketing influence were collected from the participants. It was used to determine the Marketing Influence While using distorting thinking. the participant has to describe has attitude to every sentence from 1 to 6 .

\subsection{Design and Procedure}

Data was collected from participant's measures of thinking distortions and marketing. the researcher recruited the participants for the current research. Permission to collect data was granted at an individual consent sought from them at the point of data collection.

The aims of the research along with anonymity and consent issues (including retrospective withdrawal) were explained to participants. Moreover, researchers answered questions about questionnaire items.

The current study used a correlation survey design. Data analysis was completed using Pearson analysis to test the hypotheses.

\section{Results}

The results in Table 1 show that cognitive distortion significantly related positively to marketing $(r=0.49, \mathrm{p}<0.05)$. there is a positive correlation between Binocular Vision Cognitive distortion marketing $(r=0.21, p<0.05)$ and between using polarized thinking Cognitive distortion marketing $(r=0.21, p<0.05)$ and between Should or must thinking Cognitive distortion marketing $(\mathrm{r}=0.35, \mathrm{p}<0.05)$ and between Catastrophizing Cognitive distortion marketing.

Table 1. Summary of correlations between the Cognitive Distortion and marteting

\begin{tabular}{ll} 
Variable & marketing \\
Cognitive Distortion & $0.49 *$ \\
\hline
\end{tabular}

*p $<0.05$

\section{Discussion}

The purpose of the current study was to examine the relation between the Cognitive Distortion marketing among Arabs in Israel. The results indicated that cognitive distortion positively related to marketing. there is a positive correlation between Binocular Vision Cognitive distortion marketing and between using polarized thinking Cognitive distortion marketing and between Should or must thinking Cognitive distortion marketing, similarly, between Catastrophizing Cognitive distortion marketing. This finding is in line with Nasir, et al. (2011) results that cognitive distortion is associated with marketing and misleading the buyers to buy things.

Therefore, the researchers recommend that appropriate cognitive thinking should be used in marketing, this will increase earning and encourage marketing.

\section{Limitations}

Considering the weakness of correlation in the current research, it may be argued that that the relationships among the variables investigated actually imply causal relationships between the variables. So, future research is required with more casual examination.

\section{Conclusion}

Cognitive distortion has a greater relationship marketing. To these end, future researchers should focus on the connections between distorted thinking and maximizing earning in marketing

\section{References}

Bahrami, D., \& Bahrami, M. A. (2015). The Relationship of Self-Esteem and Achievement Goals with Academic Performance. African Journal of Basic \& Applied Sciences, 7(1), 65-72. https://doi.org/10.5829/idosi.ajbas.2015.7.1.9324

Beck, A.T. (1985). "Theoretical perspectives on clinical anxiety". In Anxiety and the anxiety disorders, Edited by: Tuma, A.H. and Maser, J.D. 183-198. Hillsdale, NJ: Erlbaum.

Leitenberg, H., Yost, L. W., \& Carroll-Wilson, M. (1986). Negative cognitive errors in children: Questionnaire 
development, normative data, and comparisons between children with and without self-reported symptoms of depression, low self-esteem, and evaluation anxiety. Journal of Consulting and Clinical Psychology, 54, 528-536. https://doi.org/10.1037/0022-006X.54.4.528

Nasir, R., Zainah, A. Z. Khairudin, R., Ismail, R. Yusooff, F., \& Lukman, Z. M. (2011). Psychological factors of self-esteem and cognitive distortion in prostitution. World Applied Sciences Journal, 12, 35-39.

Nevid, J. S., \& Rathus, S. A. (2005). Psychology and the challenges of life. United State America, John Wiley \& Sons, INC.

Weems, C. F., Berman, S. L., Silverman, W. K., \& Saavedra, L. M. (2001). Cognitive errors in youth with anxiety disorders: The linkages between negative cognitive errors and anxious symptoms. Cognitive Therapy and Research, 25, 559-575. https://doi.org/10.1023/A:1005505531527

\section{Copyrights}

Copyright for this article is retained by the author(s), with first publication rights granted to the journal.

This is an open-access article distributed under the terms and conditions of the Creative Commons Attribution license which permits unrestricted use, distribution, and reproduction in any medium, provided the original work is properly cited. 